\title{
Women's work in farming, child feeding practices and nutritional status among under-five children in rural Rukwa, Tanzania
}

\author{
Sunniva Nordang ${ }^{1 *}$, Tiransia Shoo ${ }^{2}$, Gerd Holmboe-Ottesen ${ }^{2}$, Joyce Kinabo ${ }^{3}$ and Margareta Wandel ${ }^{1}$ \\ ${ }^{1}$ Department of Nutrition, University of Oslo, 0317 Oslo, Norway \\ ${ }^{2}$ Department of Community Medicine, University of Oslo, O318 Oslo, Norway \\ ${ }^{3}$ Department of Food Science and Technology, Sokoine University of Agriculture, PO Box 3000 Chuo Kikuu, Morogoro, Tanzania
}

(Submitted 24 January 2015 - Final revision received 15 July 2015 - Accepted 21 July 2015 - First published online 5 October 2015)

\begin{abstract}
Some progress has been achieved in reducing the prevalence of undernutrition among children under 5 years of age in Tanzania. In the Rukwa region (2010), the level of stunted and underweight children was 50.4 and $13.5 \%$, respectively. The aim of this study was to assess the nutritional status of children under 5 years of age, feeding practices and risk factors of undernutrition in a rural village in the Rukwa region, as well as to discuss the results in light of a similar study conducted in 1987/1988. This cross-sectional study was conducted in 152 households with children under 5 years of age. Data were obtained from the child's main caretaker and the household head, using a structured questionnaire and a $24 \mathrm{~h}$ dietary recall. Children's length/height and weight were measured. The prevalence of stunting and underweight was found to be 63.8 and $33.6 \%$ (Z-score $<-2$ of WHO 2006 CGS), respectively. Sugar-water was given to $72 \cdot 3 \%$ of the children on the first day after birth. A thin gruel was introduced after a median of 2 months (25th-75th percentiles; $1-3)$. The time mothers spent farming was a significant risk factor for stunting $(P=0.04)$. Illness, food shortage and dry-season cultivation were significant risk factors for underweight $(P<0.01)$. Using the NCHS/WHO 1983 growth reference ( $<75 \%$ of the median), the prevalence of underweight was $25.0 \%$, similar to that reported in 1987/1988 (26.4\%). In conclusion, the underweight prevalence was found to be at the same level in 2010 as was recorded in $1987 /$ 1988. Current child-feeding practices were not in line with WHO recommendations. Women working in farms, food shortage, dry-season cultivation and diseases partly explain the children's poor nutritional status.
\end{abstract}

\section{Key words: Undernutrition: Malnutrition: Child-feeding practices: Women working in farms: Tanzania}

Undernutrition in childhood continues to be a major public health problem in developing countries. The detrimental consequences of sub-optimal growth, including undernutrition, in early childhood are well-established $^{(1)}$. Low birth weight or stunting (low height for age) during the first 2-3 years of life increases the risk of death, impairs the physical and mental development of the child, affecting later health and productivity, which in turn might impact on the next generation and on societal development in general $^{(1-3)}$.

The causes of undernutrition differ from one location to another, and may include sub-optimal feeding practices and infectious diseases, food insecurity, caregivers' limited opportunities to provide care, inadequate health services, lack of knowledge and poverty ${ }^{(1)}$.

Globally, progress is being made to reduce the prevalence of undernutrition among children under 5 years of age ${ }^{(1)}$. However, trend analyses for the African region in general, and East Africa in particular, show projections of an increasing number of stunted children under 5 years of age until $2020^{(4)}$. To reduce the level of undernutrition, the government of
Tanzania has developed several strategies and policies; however, since the campaign on vitamin A supplementation/de-worming was initiated in 2001, there have been no major national efforts to reduce the level of undernutrition ${ }^{(5,6)}$. According to the most recent nutrition survey (2015), Tanzania has a very high level of stunting, despite a decrease in the last few years, and a low (and stable) level of wasting (low weight-for-height) ${ }^{(7)}$. The level of underweight (low weight-for-age) is moderate, and Tanzania is very close to reach the target for reduction in underweight to fulfil the millennium development goals ${ }^{(7)}$.

The rural poor face the highest burden of undernutrition in Tanzania. The Rukwa region, one of the least-developed regions in the country, has one of the highest prevalence rates of stunting in children under 5 years of age (50.4\%). In 2010 , the prevalence of underweight and wasting were 13.5 and $8.5 \%$, respectively ${ }^{(8,9)}$. The prevalence of stunting, underweight and wasting were similar in the nutrition survey conducted in $2015^{(7)}$. At the same time, the region is described as the 'food basket' of Tanzania with a relatively low rate of food

Abbreviation: DDS, Diet Diversity Score.

* Corresponding author: S. Nordang, email sunniva.nordang@gmail.com 
poverty $^{(9,10)}$. Nevertheless, depleted household food stores are common in the pre-harvest period - the 'hunger season',(11).

In $1987 / 1988$, a study was undertaken in a rural village in Rukwa, where the focus was to assess the nutritional situation among children under 5 years of age in relation to women's role as 'nutrition mediators' in the household, including their role as food producers ${ }^{(12-14)}$. Few new studies exist on child-feeding practices and risk factors of undernutrition in the western area of Tanzania $^{(9,11)}$. The aim of the present study was to assess the nutritional status of children under 5 years of age, child-feeding practices and other risk factors of undernutrition (including women's farming activities), as well as to discuss the findings in the light of results from the study conducted in $1987 / 1988^{(12)}$.

\section{Methods \\ Study design}

This cross-sectional study included 152 children, and it was conducted between August and December 2010 in Sumbawanga district, Rukwa region, in western Tanzania. One rural village (the same as in 1987/1988) was selected on purpose in order to discuss the results in the light of the earlier findings. The main caretaker of the child and the household head were interviewed face to face in Kiswahili by one of the authors (T. S.) using a structured questionnaire that was developed based on the study from 1987/1988. In addition, dietary data were collected with a $24 \mathrm{~h}$ recall, and anthropometric measurements were taken of the children. The questionnaire and dietary recall were pre-tested in fifteen households.

Ethics approval was obtained from the National Institute of Medical Research in Tanzania (NIMR) and the Regional Committee for Medical Research Ethics in Norway. Written consent or thumb print was obtained from all the main caretakers and household heads who participated in our study.

\section{Study area}

The selected village is located in Sumbawanga rural district. Most people in this area are subsistence farmers cultivating maize and to a smaller extent beans, groundnuts, sunflower, finger millet and wheat, in addition to vegetables such as green leafy vegetables, tomatoes, onions and potatoes. The climate is uni-modal, with the rainy season lasting from approximately October/November to May/June. The crops are usually planted at the beginning of the rainy season, followed by weeding and main harvest from June to August. During the dry season, there is access to irrigation from brooks and springs.

\section{Participants and sampling}

The study participants included the following: one child $<5$ years of age from each of the 152 households, the child's main caretaker (in 151 households the mother was the main caretaker) and the household head (in twelve households the mother was the household head). The sample size calculation was based on statistical power ( $95 \% \mathrm{CI}$, absolute precision of $7 \%$ ), the Tanzania Demographic and Health Survey (TDHS) 2004/2005 prevalence of underweight (24.5\%) and a $5 \%$ non-response rate. In each sub-division of the village, there were close to updated lists of the households, and they were used for the sampling process. Proportion-to-size sampling procedure was used to randomly select households from three sub-divisions using the household lists. Households without children under 5 years of age and those who became residents of the village after September 2009 were excluded. About 160 households with children under 5 years of age were selected for the study, of which five declined to participate and three were omitted because they were not at home, despite repeated visits by the interviewers.

\section{Data}

The $24 \mathrm{~h}$ dietary recall provided data on the number of feedings and the types (not amounts) of food items and beverages the child had consumed the previous day/night. The data were collected using a $24 \mathrm{~h}$ recall sheet, which was based on a standard sheet developed by Gibson ${ }^{(16)}$. The recall was performed in the same way as in the study of $1987^{(13,14)}$. To reduce memory lapses, the mothers were asked in a manner so that they could visualise the previous day, what they did in the morning, when the target child woke up, what the target child was fed when she/he woke up and so on. The recall data were used for the calculations of feeding frequency, including all feeding events, both meals and snacks, and both milk feeds and solid/semi-solid feeds as recommended by the $\mathrm{WHO}^{(17)}$.

A Diet Diversity Score (DDS), based on the $24 \mathrm{~h}$ recall, was developed for each child and was used to describe nutrient adequacy of the diet. It was defined as the number of food groups consumed by the child over a period of $24 \mathrm{~h}^{(18)}$. Consumption of a given food group scored one in the DDS.

For non-breast-fed children (the majority of children was $>23$ months of age), the DDS was created from the following nine food groups: grains, legumes/nuts, dairy products, eggs, flesh foods (meat and fish), vitamin A-rich vegetables/fruits, other vegetables, other fruits and oils/fats. As no international consensus has been established on the optimal composition and number of food groups to assess the adequacy of the diet in this age group, the method used in this study is based on two similar studies on non-breast-fed children ${ }^{(18,19)}$. DDS has been found to be a fairly good indicator of nutritional adequacy of the diet of non-breast-fed children ${ }^{(18-20)}$. On the other hand, for children of 6-23 months of age (of whom most children where breast-fed), WHO has recommended the use of a validated DDS consisting of seven food groups ${ }^{(17,21,22)}$ - namely, grains/roots and tubers, legumes and nuts, dairy products, flesh foods, eggs, vitamin A-rich fruits and vegetables and other fruits and vegetables. In addition, a 'minimum dietary diversity' - that is, consumption of at least four of the seven food groups - was created as it is associated with 'better quality diets' for both breast-fed and non-breast-fed children ${ }^{(17,21,22)}$.

The structured questionnaire provided information on children's health status, infant-feeding practices, number of days spent in farming by the mothers, household's food availability and the socio-demographic and socio-economic situation of the households. Children's date of birth was collected from health cards. Data on morbidities such as diarrhoea, fever, cough and 
vomiting 2 weeks before the interview were obtained from the mothers (the mothers subjective assessments). Questions concerning breast-feeding and infant-feeding practices were asked retrospectively, and included length of breast-feeding, length of exclusive breast-feeding (defined as intake of breast milk only ${ }^{(17)}$ ), introduction of complementary foods (refers to the introduction of soft, semi-solid and/or solid food items in addition to breast milk ${ }^{(17)}$ ) and 'pre-lacteals' (defined as giving fluids or feeds within the first $3 \mathrm{~d}$ after birth).

Anthropometric measurements (weight and length/height) were taken of the target children during the post-harvest/ planting period by trained personnel (the first and second author) following standardised procedures and calibrated schedules. A SECA digital uni-scale was used to measure weight to the nearest $0.1 \mathrm{~g}$, and a wooden three-piece length board was used for measuring length/height to the nearest $0 \cdot 1 \mathrm{~cm}$. Supine length was measured for children $<2$ years of age and standing height for children $>2$ years of age.

Nutritional status was defined using cut-off points of the $Z$-scores generated by relating the anthropometric measurements to the WHO growth references (2006) ${ }^{(23)}$. Stunting was defined as height-for-age $Z$-scores $(\mathrm{HAZ})<-2$, underweight as weightfor-age $Z$-scores (WAZ) $<-2$ and wasting as height-for-weight $Z$-scores (WHZ) $<-2^{(23)}$. $Z$-scores $<-3$ were classified as 'severely stunted', 'severely underweight' and 'severely wasted'. NCHS/WHO growth reference for weight-for-age (1983) ${ }^{(24)}$ and percent deviation from the reference median was used to compare the results with the study from $1987 / 1988^{(14)}$. Children $<75 \%$ of the reference median were defined as underweight.

The number of days the mothers spent farming was estimated from frequency (i.e. times/week) and period (number of weeks) of agricultural activities (clearing, ploughing/hoeing, planting, weeding and harvesting) in cultivation of various crops (maize, beans, finger millet, groundnuts, wheat and sunflower) during the last main agricultural season (October/ November 2009-July 2010). These estimations did not include dry-season (irrigated) farming. Participation in dry-season (irrigated) farming was assessed through a question with dichotomous response categories (yes/no). Data on whether or not the children were brought to the agricultural fields, what they were fed there and who cared for the children who were left behind were based on the mothers' report.

Based on findings from the former study ${ }^{(25)}$, the number of months without maize in stock before the last harvest was used as an indicator of food availability. Maize was the main source of food, and most of the households found it difficult to procure food for more than a month's supply from other sources due to shortage of cash. The households were divided into those with 'food available' (no months without maize in stock before the last harvest) or those with 'food shortage' ( $\geq 1$ month without maize in stock before the last harvest)

An index of the households' economical situation was constructed based on possession of assets. The assets were selected and rated after discussions with the village leaders and other representatives of the village. The rating was carried out according to the monetary value in the market ranging from 1 to 200: wrist watch (1), radio (2), mobile phone (6), chair/ table (7), sofa/table (20), cupboard (20), plough (20), sewing machine (25), TV (40), milling machine (200) and motorcycle (200). In each household, the values were summarised to construct the index.

\section{Statistical analysis}

The WHO Anthro software version 3.1.0 (http://who-anthro. software.informer.com/3.1/) was used for calculations of nutritional status. Statistical package for social science version 18 was used to analyse the data.

Frequency distributions, median and the 25 th -75 th percentile or range, mean and standard deviation or CI were used. Pearson's $\chi^{2}$ test was used to test for differences between the sexes in nutritional status.

Risk factors for stunting and underweight were assessed using the $\chi^{2}$ test and logistic regression and were identified with purposeful selection of independent variables. The following variables were tested for association with the dependent variables (HAZ $<-2$ and WAZ $<-2$ ): age, sex, breast-fed at time of the interview, illness the last 2 weeks, feeding frequency, mothers' and fathers' level of education (primary school, uncompleted $v$. primary school and above) and other incomegenerating activities (e.g. for women, mainly beer brewing; for men, mainly farming), number of children under 5 years of age in the household ( $\geq 2 v . \leq 1)$, number of days the women spent farming, food availability, dry-season cultivation and indicator of household economy.

The independent variables that did not show a linear relationship with the dependent variable were divided into categories. The cut-offs were set after inspecting the frequency distribution of the sample in order to reflect the situation in the community. Time in number of days the women spent farming was divided into three categories, so that the categories were approximately equal in size $(\leq 36,37-63$ and $\geq 64 d)$. The index of the households' economic situation was also divided into three equal-sized categories: 'poor', 'average' and 'good', relative to the village situation. Feeding frequency was divided into three categories of approximately equal size $(\leq 2,3$ and $\geq 4$ feedings). The last category, four feedings or more, connotes the recommended feeding frequency by the $\mathrm{WHO}^{(17)}$. The independent variables included in the preliminary model were those with a $P$ value $<0.25$ in the $\chi^{2}$ tests and those with clinical or known importance - that is, age, disease and economic indicator. All the variables were tested for multi-collinearity.

A separate analysis, using logistic regression, was conducted to explore the association between DDS and stunting $(\mathrm{HAZ}<-2)$ and underweight (WAZ <-2) among non-breast-fed children. DDS was divided into three categories of approximately equal size $(\leq 4,5$ and $\geq 6$ ), and the adjusted analysis was adjusted for age, disease and time mothers spent farming.

\section{Results}

\section{Characteristics of the sample}

Nearly all women ( $>90 \%$ ) reported farming as their main occupation, and most women (70\%) reported additional income-generating activities. These numbers were higher for 
Table 1. Socio-demographic characteristics of households and household members in a population of 152 households in rural Rukwa, Tanzania, August to November 2010

(Numbers and percentages)

\begin{tabular}{|c|c|c|}
\hline & $n$ & $\%$ \\
\hline $\begin{array}{l}\text { Child age (median, 25th-75th percentile) } \\
\text { (months) }\end{array}$ & $30 \cdot 8$ & $17 \cdot 1-43 \cdot 7$ \\
\hline \multicolumn{3}{|l|}{ Main caretaker/women $(n$ 152) } \\
\hline Main occupation farming & 141 & $92 \cdot 8$ \\
\hline Petty trade & 4 & $2 \cdot 6$ \\
\hline Other ${ }^{\star}$ & 7 & 4.6 \\
\hline $\begin{array}{l}\text { Other income-generating activity (mainly } \\
\text { beer brewing) }\end{array}$ & 108 & $71 \cdot 1$ \\
\hline \multicolumn{3}{|l|}{ Education } \\
\hline No formal education & 56 & $36 \cdot 8$ \\
\hline Primary school, not finished & 22 & 14.5 \\
\hline Primary school and above & 74 & $48 \cdot 8$ \\
\hline Secondary school and above & 4 & $2 \cdot 7$ \\
\hline \multicolumn{3}{|l|}{ Men $(n 140)$} \\
\hline Main occupation farming & 110 & $78 \cdot 6$ \\
\hline Business & 15 & $10 \cdot 7$ \\
\hline Craftsman & 8 & $5 \cdot 7$ \\
\hline Other† & 7 & $5 \cdot 0$ \\
\hline $\begin{array}{l}\text { Other income-generating activity (mainly } \\
\text { farming) }\end{array}$ & 52 & $37 \cdot 1$ \\
\hline \multicolumn{3}{|l|}{ Education } \\
\hline No formal education & 18 & $12 \cdot 9$ \\
\hline Primary school, not finished & 29 & $20 \cdot 9$ \\
\hline Primary school and above & 92 & $66 \cdot 2$ \\
\hline Secondary school and above & 10 & $7 \cdot 2$ \\
\hline \multicolumn{3}{|l|}{ Household } \\
\hline Female headed & 12 & 7.9 \\
\hline Polygamous & 16 & 11.4 \\
\hline$\geq 2$ under-five children & 86 & $56 \cdot 6$ \\
\hline Main source of food from own harvest & 139 & 91.4 \\
\hline Perform dry-season cultivation ( $n$ 148) & 106 & 71.6 \\
\hline Food availableł & 56 & $41 \cdot 2$ \\
\hline Food shortageł & 80 & $58 \cdot 8$ \\
\hline \multicolumn{3}{|l|}{ Economic indicator } \\
\hline Poor & 54 & 35.5 \\
\hline Average & 51 & $33 \cdot 6$ \\
\hline Good & 47 & 30.9 \\
\hline
\end{tabular}

* Business, paid professional, craftsman.

† Petty trade, paid professional.

$\ddagger$ Food available (no months without maize in stock before last harvest) $v$. food shortage ( $\geq 1$ month without maize in stock before last harvest), $n 136$

women than for men (Table 1). The overall level of schooling was low, and most families (>90\%) participated in subsistence farming. Approximately $70 \%$ of the households performed dry-season cultivation by irrigation (Table 1).

\section{Children's nutritional status}

Table 2 presents the prevalence of stunting and underweight, using different classification systems, growth curves and cutoffs. The prevalence of stunting, severe stunting included, was very high $-63.8 \%$. The prevalence of both stunting and underweight increased with age. Stunting was over $70 \%$ at 12-48 months of age, and declined thereafter, whereas the percentage of underweight remained high up to 59 months. No significant differences between sexes in the prevalence of stunting and underweight were observed. The prevalence of wasting and overweight (not included in the table) were both approximately $3 \%$.

\section{Child-feeding practices}

Fig. 1 depicts infant-feeding practices during the first 12 months of life. The majority of the participanting children were breastfed, but exclusive breast-feeding for 6 months was extremely rare $(<1 \%)$. Nearly all mothers $(98.9 \%)$ reported to have breastfed their child for 1 year (Fig. 1), whereas $60 \%$ continued breast-feeding for 2 years. Most mothers (72.4\%) reported to have introduced pre-lacteals, mainly sugar-water, during the first few days after birth, of whom more than half $(65.6 \%)$ continued with plain water after sugar-water was discontinued. Uji, a thin gruel made principally from finger millet (61.1\%) or maize $(38.9 \%)$, was introduced at median 2 months of age (25th-75th percentiles; $1-3$ months) after birth. Ugali, a stiff porridge made mainly of maize, and part of the family food, was introduced after median 6 months of age (range 3-12). Ugali was usually consumed with a bean stew and/or a relish made out of green leafy vegetables. Tomatoes, onions and oil were frequently used in the relish and bean stew.

All the non-breast-fed children had eaten foods based on grains the previous day (mainly maize). Most of these children (>80\%) had consumed 'other vegetables' (mainly tomatoes and onions) and beans/groundnuts. More than half (>60\%) had consumed vitamin A-rich fruits and vegetables (mainly green leafy vegetables) and approximately $40 \%$ consumed flesh foods (mainly fish - sardines). Few children consumed milk (10\%), 'other fruits' $(<5 \%)$ and egg (1\%). Oil was frequently used for cooking ( $>60 \%$ of the households), and sugar cane was commonly used as a snack (>90\%).

Mean DDS among the non-breast-fed children was 4.7 (SD 1.1). DDS was not associated with stunting or underweight among the non-breast-fed children. Mean feeding frequency among the non-breast-fed children was $3 \cdot 1$ (sD 0.8). Among the children between 6 and 23 months of age, $53.5 \%$ ( $n 23)$ had the recommended minimum DDS or higher $(\geq 4)$, and approximately $25 \%$ ( $n$ 11) were fed only one or two food groups.

\section{Women working in farms}

Women worked a median of 48 (range 5-208) d in the field in the agricultural season of 2009/2010. A majority of women $(60 \cdot 6 \%)$ were found to bring their young children ( $<2$ years of age) to the farming fields; $86.7 \%$ of the children brought to the field were fed mainly uji (a thin gruel). Most of the children $(85.2 \%)$ not brought to the field were fed by an older sibling $(<15$ years of age)

\section{Factors associated with stunting and underweight}

Logistic regression analyses were used to explore the factors associated with stunting and underweight (Tables 3 and 4). In the fully adjusted regression model (containing age, illness, feeding frequency, indicator of food availability, time women spent farming and economic indicator), children were more likely to be stunted when the mothers spent more days farming in the last agricultural season $(P=0 \cdot 04)$ (Table 3 ). In the regression model using underweight as the dependent variable and including age, illness, fathers' level of education, time women spent farming, food availability, dry-season cultivation 
Table 2. Nutritional status in a population of 152 children under 5 years of age in rural Rukwa, Tanzania, August to November 2010 (Median values and 25 th, 75 th percentiles)

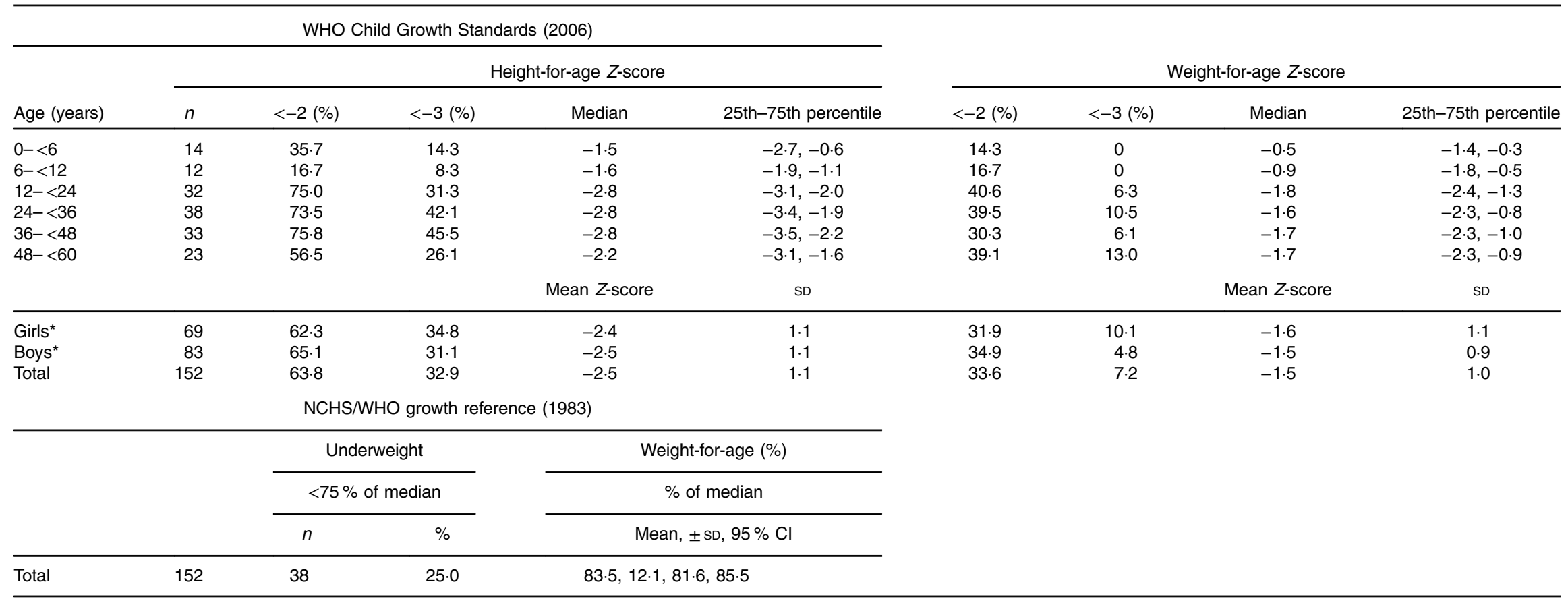

* No significant difference between the groups (Pearson's $x^{2}$ test). 
and economic indicator as the independent variables, children were more likely to be underweight if they were sick (diarrhoea, fever, cough or vomiting) during the last 2 weeks before the interview $(P<0 \cdot 01)$, if they came from households with food

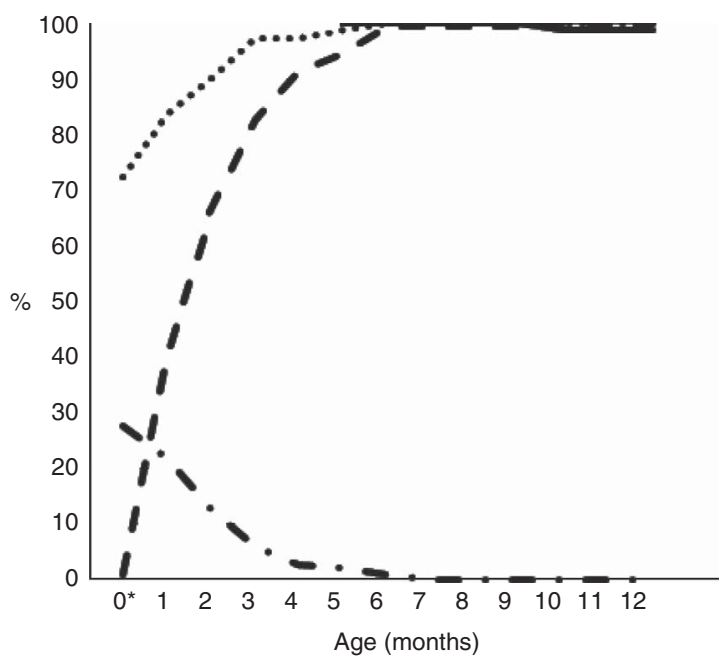

Fig. 1. Infant-feeding pattern for the first 12 months of age, based on recall data, in a population of $152^{*}$ children under 5 years of age in rural Rukwa, Tanzania, August to November 2010. . - . - , Exclusive breast-feeding (BF) ( $n$ 152); - length of BF ( $n$ 96); ..........., introduction sugar-water ( $n 152)$; - - , introduction uji (a thin gruel) $(n$ 149) shortage $(P<0.01)$ or if the household carried out dry-season cultivation $(P<0 \cdot 01)$ (Table 4$)$.

\section{Discussion}

\section{Prevalence and risk factors of undernutrition}

The overall prevalence of stunting $(63.8 \%)$ and underweight (33.6\%) among children under 5 years of age in this study is categorised as very high according to the WHO criteria ${ }^{(26)}$, and indicates a major public health problem in the village. These prevalence rates are much higher than what has been found in studies conducted in other parts of Rukwa ${ }^{(11)}$, Tanzania ${ }^{(8,27,28)}$ and other East African countries, ${ }^{(29)}$ highlighting the large disparities in undernutrition in different locations and population groups.

The rate of stunting increased from $27 \%$ for children $<12$ months to $75 \%$ for those between 12 and 24 months of age. This is consistent with earlier reports where child growth has been found to falter in early childhood in low- and middle-income countries $^{(29,30)}$. The high stunting prevalence, combined with infant-feeding practices deviating from current recommendations found in the present study, indicates a potential for dietary improvement during the first few years of life.

According to our findings, the children's diets can be described as poor. WHO recommends exclusive breast-feeding of infants for the first 6 months of life ${ }^{(31)}$. In the studied village,

Table 3. Factors associated with stunting in crude and adjusted logistic regression analysis in a population of 152 children under 5 years of age in rural Rukwa, Tanzania, August to November 2010

(Odds ratios and $95 \%$ confidence intervals)

\begin{tabular}{|c|c|c|c|c|c|c|}
\hline \multirow[b]{2}{*}{ Stunting } & \multirow[b]{2}{*}{$n 152$} & \multirow[b]{2}{*}{ Stunted (\%) } & \multicolumn{2}{|c|}{ Crude } & \multicolumn{2}{|c|}{ Adjusted $†$} \\
\hline & & & OR & $95 \% \mathrm{Cl}$ & OR & $95 \% \mathrm{Cl}$ \\
\hline \multicolumn{7}{|l|}{ Breast-fed $\ddagger$} \\
\hline No & 96 & $70 \cdot 8$ & 1 & & - & \\
\hline Yes & 56 & $51 \cdot 8$ & $0.4^{\star *}$ & $0.2,0.9$ & & \\
\hline \multicolumn{7}{|c|}{ Age (months) } \\
\hline$\leq 21$ & 51 & $49 \cdot 0$ & 1 & & 1 & \\
\hline $22-38$ & 51 & $78 \cdot 4$ & $3 \cdot 8$ & $1.6,8.9$ & $2 \cdot 3$ & $0 \cdot 6,7 \cdot 7$ \\
\hline$\geq 38$ & 50 & $64 \cdot 0$ & $1 \cdot 8$ & $0.8,4 \cdot 1$ & 1.2 & $0.4,3 \cdot 6$ \\
\hline \multicolumn{7}{|l|}{ Illness } \\
\hline Absent & 68 & 64.7 & 1 & & 1 & \\
\hline Present & 84 & 63.1 & 0.6 & $0.3,1.4$ & $1 \cdot 2$ & $0.5,3 \cdot 0$ \\
\hline \multicolumn{7}{|c|}{ Feeding frequency } \\
\hline$\leq 2$ & 32 & 53.0 & 0.7 & $0 \cdot 2,2 \cdot 1$ & 0.7 & $0 \cdot 2,2 \cdot 3$ \\
\hline 3 & 67 & 74.6 & 1.5 & $0.6,3 \cdot 8$ & 1.6 & $0.6,4.7$ \\
\hline$\geq 4$ & 35 & $62 \cdot 9$ & 1 & & 1 & \\
\hline \multicolumn{7}{|c|}{ Food available $\ddagger$} \\
\hline Yes & 56 & $60 \cdot 7$ & 1 & & 1 & \\
\hline No & 80 & $71 \cdot 2$ & 1.6 & $0.8,3.3$ & $2 \cdot 1$ & $0.7,6.0$ \\
\hline \multicolumn{7}{|c|}{ Women's work in farming $(d) \ddagger$} \\
\hline$\leq 36$ & 50 & $56 \cdot 0$ & 1 & & 1 & \\
\hline $37-63$ & 49 & $63 \cdot 3$ & $1 \cdot 4$ & $0.6,3 \cdot 0$ & $1 \cdot 7$ & $0 \cdot 6,4 \cdot 7$ \\
\hline$\geq 64$ & 49 & 73.5 & $2 \cdot 2^{*}$ & $0.9,5 \cdot 1$ & $3 \cdot 1^{* *}$ & $1.0,9.5$ \\
\hline \multicolumn{7}{|c|}{ Economic indicator } \\
\hline Poor & 54 & $66 \cdot 7$ & $1 \cdot 1$ & $0.4,2.4$ & 0.6 & $0 \cdot 2,2 \cdot 1$ \\
\hline Average & 51 & 58.8 & 0.7 & $0.3,1.7$ & 0.4 & $0.1,1 \cdot 3$ \\
\hline Good & 47 & $66 \cdot 0$ & 1 & & 1 & \\
\hline
\end{tabular}

Values were significantly different between the reference level and other levels within given characteristics * $P<0.1,{ }^{\star *} P<0.05$.

$\dagger$ Breast-feeding was excluded in the adjusted model due to multi-collinearity with age.

$\mp$ Breast-fed at the time of interview, food available (no months without maize in stock before the last harvest) $v$. food shortage ( $\geq 1$ month without maize in stock before the last harvest), $n 136$, feeding frequency (number of feedings per day), women working in farms is number of days women spent on farming the last season (except dry-season cultivation). 
Table 4. Factors associated with underweight in crude and adjusted logistic regression analysis in a population of 152 children under 5 years of age in rural Rukwa, Tanzania, August to November 2010

(Odds ratios and $95 \%$ confidence intervals)

\begin{tabular}{|c|c|c|c|c|c|c|}
\hline \multirow[b]{2}{*}{ Underweight } & \multirow[b]{2}{*}{$n 152$} & \multirow[b]{2}{*}{ Underweight (\%) } & \multicolumn{2}{|c|}{ Crude } & \multicolumn{2}{|c|}{ Adjusted $\dagger$} \\
\hline & & & OR & $95 \% \mathrm{Cl}$ & OR & $95 \% \mathrm{Cl}$ \\
\hline \multicolumn{7}{|l|}{ Breast-fed $\neq$} \\
\hline No & 96 & 38.5 & 1 & & - & \\
\hline Yes & 56 & $25 \cdot 0$ & $0.5^{\star}$ & $0.3,1 \cdot 1$ & & \\
\hline \multicolumn{7}{|l|}{ Age (months) } \\
\hline$\leq 21$ & 51 & 29.4 & 1 & & 1 & \\
\hline $22-38$ & 51 & $35 \cdot 3$ & 1.3 & $0.5,3.0$ & $1 \cdot 2$ & $0.3,4.4$ \\
\hline$\geq 38$ & 50 & $36 \cdot 0$ & $1 \cdot 3$ & $0.6,3 \cdot 1$ & 1.4 & $0.4,4.7$ \\
\hline \multicolumn{7}{|l|}{ Illnēss } \\
\hline Absent & 68 & $19 \cdot 1$ & 1 & & 1 & \\
\hline Present & 84 & $45 \cdot 2$ & $3.5^{\star \star \star}$ & $1 \cdot 7,7.3$ & $4 \cdot 4^{\star \star \star}$ & $1 \cdot 6,12 \cdot 4$ \\
\hline \multicolumn{7}{|c|}{ Father education $\ddagger$} \\
\hline Lower & 47 & 23.4 & 1 & & 1 & \\
\hline Higher & 92 & $37 \cdot 0$ & $1 \cdot 8$ & $0.8,4 \cdot 2$ & 1.5 & $0.5,4.4$ \\
\hline \multicolumn{7}{|c|}{ Women’s work in farming (d) $\ddagger$} \\
\hline$\leq 36$ & 50 & $20 \cdot 0$ & 1 & & 1 & \\
\hline $37-63$ & 49 & $28 \cdot 6$ & 1.6 & $0 \cdot 6,4 \cdot 1$ & 1.8 & $0.5,5 \cdot 8$ \\
\hline$\geq 64$ & 49 & $51 \cdot 0$ & $4 \cdot 2^{\star * \star}$ & $1 \cdot 7,10 \cdot 2$ & $2 \cdot 6^{*}$ & $0.8,8 \cdot 7$ \\
\hline \multicolumn{7}{|c|}{ Food available } \\
\hline Yes & 56 & $19 \cdot 6$ & 1 & & 1 & \\
\hline No & 80 & $42 \cdot 5$ & $3 \cdot 0^{* * *}$ & $1.4,6 \cdot 7$ & $4 \cdot 8^{\star \star \star}$ & $1.5,14.9$ \\
\hline \multicolumn{7}{|c|}{ Dry-season cultivation } \\
\hline No & 46 & $15 \cdot 2$ & 1 & & 1 & \\
\hline Yes & 106 & 41.5 & $3 \cdot 9^{\star \star \star}$ & $1 \cdot 6,9 \cdot 7$ & $10 \cdot 7^{\star \star \star}$ & $2 \cdot 6,43 \cdot 4$ \\
\hline \multicolumn{7}{|c|}{ Economic indicator } \\
\hline Poor & 54 & $33 \cdot 3$ & $1 \cdot 1$ & $0.5,2.7$ & 0.4 & $0.1,1.5$ \\
\hline Average & 51 & $37 \cdot 3$ & 1.4 & $0.6,3.3$ & 0.6 & $0.2,2 \cdot 1$ \\
\hline Good & 47 & 29.8 & 1 & & 1 & \\
\hline
\end{tabular}

Values were significantly different between the reference level and other levels within given characteristics ${ }^{\star} P<0.1,{ }^{\star \star \star} P<0.01$.

† Breast-feeding was excluded in the adjusted model due to multi-collinearity with age.

¥ Breast-fed at the time of interview, food available (no months without maize in stock before the last harvest) $v$. food shortage ( $\geq 1$ month without maize in stock before the last harvest), $n 136$, father's education: lower (primary school, not finished) $v$. higher (primary school and above); women working in farms is number of days women spent on farming the last season (except dry-season cultivation).

there was a widespread use of sugar-water (72.4\%) and water, as well as an early introduction of complementary foods, and thus a low rate of exclusive breast-feeding. This is a common trait in Tanzania ${ }^{(32)}$ and Uganda ${ }^{(33)}$. Uji (thin gruel) has low energy and nutrient content ${ }^{(13,34)}$. Ugali (stiff porridge), on the other hand, is more energy- and nutrient-dense, especially if served with bean stew or other relishes ${ }^{(13)}$. The children's diet included a limited amount of dairy products, meat, fish and fruits, which also could explain the children's poor nutritional status. The diet could, in general, be described as inadequate to cover the dietary needs of a growing child. Only half of the children (6-23 months) consumed foods from the four food groups, which is recommended as the minimum dietary diversity by the $\mathrm{WHO}^{(17)}$. In addition, for non-breast-fed children, a DDS $<4^{(18)}$ and 5- $6^{(19)}$ has been associated with inadequate diets, and in the present study the non-breast-fed children had a mean DDS of 4.7 . Low energy density and monotonous diets in general could possibly explain the lack of association between DDS and nutritional status (both underweight and stunting) among the weaned children in this study. The association between nutritional status and DDS has been found, in other studies, to give mixed results ${ }^{(35-37)}$.

The lack of association between the economic indicator and both stunting and underweight may be explained by a relatively homogeneous population in socio-economic terms.
Those better-off tended to move out of the village to the richer town centre of the Rukwa region. Even if the ownership of assets that made up the economic index may rightfully reflect the better economic situation of a household, it could also reflect that the better-off households were more market oriented and prioritised the procurement of these assets instead of food for their children. The study conducted in 1987/1988 showed that such priorities were the basis for sex conflicts in many households, where the women wanted to keep the food stored for family consumption, whereas the men wanted to sell them in order to get access to other consumer goods ${ }^{(38)}$. A negative effect of such market orientation was also shown in the former study when two villages were compared in terms of food availability and child nutritional status. It was found that the most market oriented (the village selected for the present study) had substantially more underweight children $<5$ years of age ${ }^{(14)}$.

It is well-documented that women in rural areas of subSaharan Africa have heavy work burdens, and participate more than men in both agricultural activities and household $\operatorname{activities}^{(39,40)}$. In the present study, women worked a median of $48 \mathrm{~d}$ farming during the last agricultural season, and a higher number of days spent in farming ( $\geq 64 d$ ) was found to increase the risk of child stunting, even after adjusting for age, illness, feeding frequency, food availability and economic indicator. This might be explained by the lack of time for proper care of 
their children, despite the practice of bringing young children to the fields. Older children are commonly left in the care of female siblings $<15$ years of age, who may have limited abilities to provide adequate care, especially to undernourished children $^{(41)}$. The association between underweight and the time women spent on farm work in the present study was NS. The study from 1987/1988 found a positive association between underweight and number of feedings among non-breast-fed children, and a negative association between the time women spent on farming and feeding frequency (season of high work load), but not with underweight ${ }^{(13)}$. The lack of a significant association between the time women spent on farm work and underweight was explained by the various compensatory mechanisms such as the possibility for feeding the child in the field or having good-quality alternate caretakers ${ }^{(13)}$. Other studies have found women's work in food-related activities to have positive, negative or no association with their children's nutritional status ${ }^{(11,40,42)}$. In a study from the Rukwa region, Hadley (2005) suggests that child undernutrition during the pre-harvest season (wet season) is a consequence of increased labour demands among the women and infectious diseases rather than poor household food availability ${ }^{(11)}$. A study by Pierre-Louis et $a l .{ }^{(42)}$ found the mothers' participation in feeding to be crucial for an optimal development of the child.

The relationship between women's work and child nutritional status is complex, and it varies from region to region $^{(39,42)}$. Women's work in agriculture might have a positive impact on children's nutritional status due to an increase in household food availability, and a negative impact due to less time available for child care, included feeding ${ }^{(13)}$. In addition, control of income, women's social status, age of the child, distance to the work place and compensatory mechanisms undertaken by the women, such as the use of and quality of alternate caregivers and whether or not the mothers bring the child along to work, may have an impact on the relationship ${ }^{(40-43)}$. Women have an important role in agricultural work. To improve their situation, both men and women should be included in agricultural development projects to improve women's status relative to men, to increase the women's access to resources and the projects should integrate nutrition and health with agriculture ${ }^{(39)}$.

Disease, food insecurity and dry-season cultivation were found to be significantly associated with underweight. The link between dry-season cultivation on underweight is uncertain, and more research is needed to understand this association.

\section{The nutritional situation in 1987/1988 and 2010}

In the studied village, no substantial improvement in children's ( $<5$ years of age) nutritional status was observed from 1987/ 1988 to 2010; the prevalence of underweight (26.4 and $25 \%$, respectively) and weight-for-age as percentage of the reference median ( 81.8 and $83.5 \%$ respectively) were similar for the two time periods. Underweight prevalence in Tanzania has declined by $10 \%$ in the same time period ${ }^{(8)}$. Why has no improvement taken place in the studied village?

One explanation is that very few children were exclusively breast-fed. Under $30 \%$ were breast-fed exclusively from birth on, and $<1 \%$ were exclusively breast-fed for 6 months as recommended by the $\mathrm{WHO}^{(17)}$. Sugar-water was introduced as a pre-lacteal very early. A comparison of the results on feeding practices between the two studies showed that complementary foods were introduced earlier (at 2 months) in 2010 than in 1987/1988 (at 4-6 months). The type of complementary foods given to the children were similar in the two studies. The feeding frequencies were similar, about three in both studies. This indicates that child-feeding practices had not improved, which could partly explain the lack of improvement in nutritional status. Although studies from the Rukwa region in general have shown that the practice of giving pre-lacteals has been reduced substantially between $2004 / 2005$ and $2010(71-36 \cdot 3 \%)^{(8)}$, this seems not to be the case in the studied village.

Many days spent on farming by the women, food shortage together with poor improvements in development indices (stable high poverty levels, lack of supply of safe drinking water and lower access to health facilities), as described by Jerve et $a l .{ }^{(9)}$ in the Rukwa region between 1990 and 2009, are also likely explanations for the lack of substantial progress regarding nutritional status in the studied village.

Other explanations for the lack of progress in nutritional status could have been related to the HIV/AIDS epidemic or seasonal variations in underweight prevalence. The HIV/AIDS epidemic has changed family structures and left children orphaned and vulnerable, many left in care of their grandparents ${ }^{(44,45)}$. However, in the studied village, nearly all children (99\%) were living with their parents in traditional household constellations. Thus, this epidemic could not be a likely explanation. Furthermore, it is important to pay attention to seasonal variations when comparing two time periods, as underweight prevalence is found to vary across seasons ${ }^{(11,25)}$. A higher prevalence of underweight is usually observed during the pre-harvest period/rainy season due to food shortage, infections and more days spent on farming by women ${ }^{(11)}$. The children in the present study were measured in the post-harvest period and the children in the former study were measured (at three times) during the pre-harvest period/rainy season and the post-harvest period. Thus, it is not likely that the lack of improvements found in this study is due to seasonal variations.

\section{Limitations of the study}

The main limitation of this study was that the methods used to estimate days spent on farming and the economic indicator have not been validated. Recall bias is likely to have occurred when estimating the days spent on farming. Unfortunately, it was not possible to directly compare women working in farms in the two studies due to differences in the methods used. Further, the data analysis would have been strengthened with a larger sample size, and it would have been possible to disaggregate data according to age. In addition, the cross-sectional study design did not allow us to make conclusions regarding causal relationships.

\section{Conclusion}

The results from this study indicate that undernutrition among children is a public health problem, and that it is associated with 
women working in farms, food insecurity, dry-season cultivation and disease. In addition, child-feeding practices for the first 2 years of life were not according to international recommendations, and of special concern is the lack of exclusive breastfeeding and the early introduction and poor quality of the complementary foods. Neither the nutritional status nor the complementary feeding practices, as measured by underweight, were found to have improved substantially between 1987/1988 and 2010

Efforts should be made to develop health and nutrition promotion programmes targeting, especially, maternal and child nutrition, and emphasis should be placed on including rural remote areas. Exclusive breast-feeding promotion should be the first priority. Women's time use should be considered when strategies for agriculture are made.

\section{Acknowledgements}

The present study was not supported by any external funding.

The authors' contributions are as follows: S. N. and T. S. conducted the field work and data collection. S. N. was responsible for the literature review, statistical analysis, interpreted the results and drafted the paper. T. S., M. W. and G. H.-O. helped with the statistical analysis. M. W. and G. H.-O. contributed significantly to the interpretation of results and writing of the paper. All authors contributed to the study design, and read and approved the final version of the manuscript.

The authors declare that they have no conflicts of interest.

\section{References}

1. Black RE, Victora CG, Walker SP, et al. (2013) Maternal and child undernutrition and overweight in low-income and middle-income countries. Lancet (Epub ahead of print).

2. Black RE, Allen LH, Bhutta ZA, et al. (2008) Maternal and child undernutrition 1- maternal and child undernutrition: global and regional exposure and health consequences. Lancet ii, 243-260.

3. Victora CG, Adair L, Fall C, et al. (2008) Maternal and child undernutrition: consequences for adult health and human capital. Lancet 371, 340-357.

4. De Onis M, Blossner M \& Borghi E (2012) Prevalence and trends of stunting among pre-school children, 1990-2020. Public Health Nutr 15, 142-148.

5. Save the Children UK (2012) A Life Free from Hunger - Tackling Child Malnutrition, London, UK. http://www.savethechildren. org/atf/cf/\%7B9def2ebe-10ae-432c-9bd0-df91d2eba74a\%7D/A\% 20LIFE\%20FREE\%20FROM\%20HUNGER\%20-\%20TACKLING\% 20CHILD\%20MALNUTRITION.PDF (accessed June 2013).

6. Kinabo J (2014) The Policy Environment for Linking Agriculture and Nutrition in Tanzania - AgriDiet Working Paper 1. http://agridiet.ucc.ie/wp-content/uploads/sites/2/2014/11/ Joyce-WP2-FinalDraft-update-31-oct-2.pdf

7. Tanzania Food and Nutrition Centre (2014) Tanzania National Nutrition Survey 2014. Dar es Salaam, Tanzania. http://www.unicef.org/media/files/Tanzania_National_Nutrition_ Survey_2014_Final_Report_18012015.pdf (accessed May 2015).

8. National Bureau of Statistics, ICF Macro (2011) Tanzania Demographic and Health Survey 2010. Dar es Salam, Tanzania and Calverton, Maryland, USA. http://www.measuredhs. com/pubs/pdf/FR243/FR243[24June2011].pdf (accessed June 2013).
9. Jerve AM \& Ntemi EJK (2009) Rukwa Ruka: the attempt of a foreign donor to uplift a neglected region: a study of the impact of Norwegian aid to Rukwa Region, Tanzania. CMI Report no. R 2009:12. Bergen: Chr. Michelsen Institute. http:// www.cmi.no/publications/file/3472-rukwa-ruka-the-attemptof-a-foreign-donor-to.pdf (accessed June 2013).

10. Daily News (2013) State invests $4 \mathrm{bn} /$ - in irrigation for Rukwa. http://www.dailynews.co.tz/index.php/parliament-news/17405state-invests-4bn-in-irrigation-for-rukwa (accessed June 2013).

11. Hadley C (2005) Ethnic expansions and between-group differences in 'children's health: a case study from the Rukwa Valley, Tanzania. Am J Phys Anthropol 128, 682-692.

12. Holmboe-Ottesen $G$ \& Wandel M (1992) Nutrition, Household Food Security and Agricultural Change. With Special Focus on Gender Issues. Degree of Dr. Philos. Oslo: Institute for Nutrition Research and Centre for Development and the Environment, University of Oslo.

13. Wandel M \& Holmboe-Ottesen G (1992) Womens work in agriculture and child nutrition in Tanzania. J Trop Pediatr 38, 252-255.

14. Wandel M \& Holmboe-Ottesen G (1992) Child malnutrition and development process in two Tanzanian villages. Health Policy Plan 7, 123-134.

15. National Bureau of Statistics and ORC Macro (2005) Tanzania Demographic and Health Survey 2004-05. Dar es Salaam, Tanzania and Calverton, Maryland, USA. http://www.measuredhs. com/pubs/pdf/FR173/FR173-TZ04-05.pdf (accessed June 2013).

16. Gibson RS (2005) Principles of Nutritional Assessment, 2nd ed. pp. 41-44. New York: Oxford University Press.

17. World Health Organization (2008) Indicators for Assessing Infant and Young Child Feeding Practices - Part 1: Definitions. Geneva: WHO. http://www.who.int/nutrition/publications/ infantfeeding/9789241596664/en/ (accessed March 2015).

18. Steyn NP, Nel JH, Nantel G, et al. (2006) Food variety and dietary diversity scores in children: are they good indicators of dietary adequacy? Public Health Nutr 9, 644-650.

19. Kennedy GL, Pedro MR, Seghieri C, et al. (2007) Dietary diversity score is a useful indicator of micronutrient intake in non-breast-feeding Filipino children. J Nutr 137, 472-477.

20. Hatloy A, Torheim LE \& Oshaug A (1998) A food variety - a good indicator of nutritional adequacy of the diet? A case study from an urban area in Mali, West Africa. Eur J Clin Nutr 52, 891-898.

21. Working Group on Infant and Young Child Feeding Indicators (2006) Developing and validating simple indicators of dietary quality and energy intake of infants and young children in developing countries: Summary of findings from analysis of 10 data sets. Report submitted to: the Food and Nutrition Technical Assistance (FANTA) Project/Academy for Educational Development (AED). Washington, DC. FANTA. http://www. fantaproject.org/sites/default/files/resources/IYCF_Datasets_ Summary_2006.pdf (accessed March 2015).

22. Working Group on Infant and Young Child Feeding Indicators (2007) Developing and validating simple indicators of dietary quality of infants and young children in developing countries: Additional analysis of 10 data sets. Report submitted to: the Food and Nutrition Technical Assistance (FANTA) Project/ FHI 360). Washington, DC, FANTA. http://www.fantaproject. org/sites/default/files/resources/IYCF_Datasets_2007.pdf (accessed March 2015).

23. World Health Organization Multicentre Growth Reference Study Group (2006) WHO Child Growth Standards: Length/ Height-for-Age, Weight-for-Age, Weight-for-Length, Weightfor-Height And Bmi-for-Age: Methods and Development. Geneva: WHO, Department of Nutrition for Health and Development. http://www.who.int/childgrowth/standards/ Technical_report.pdf (accessed June 2013). 
24. World Health Organization (1983) Measuring Change in Nutritional Status: Guidelines for Assessing the Nutritional Impact of Supplementary Feeding Programmes for Vulnerable Groups. Geneva: WHO.

25. Wandel M \& Holmboe-Ottesen G (1992) Food availability and nutrition in a seasonal perspective - a study from the rukwa region in Tanzania. Hum Ecol 20, 89-107.

26. World Health Organization (1995) Physical status: the use and interpretation of anthropometry. Report of a WHO Expert Committee. WHO Technical Report Series 854. Geneva: WHO. http://whqlibdoc.who.int/trs/WHO_TRS_854.pdf (accessed June 2013)

27. Nyaruhucha CNM, Msuya JM, Mamiro PS, et al. (2006) Nutritional status and feeding practices of under-five children in Simanjiro District, Tanzania. Tanzan Health Res Bull 8, 162-167.

28. Abubakar A, Uriyo J, Msuya SE, et al. (2012) Prevalence and risk factors for poor nutritional status among children in the Kilimanjaro region of Tanzania. Int I Environ Res Public Health 9, 3506-3518.

29. Bloss E, Wainaina F \& Bailey RC (2004) Prevalence and predictors of underweight, stunting, and wasting among children aged 5 and under in western Kenya. $J$ Trop Pediatr. 50, $260-270$

30. Victora CG, de Onis M, Hallal PC, et al. (2010) Worldwide timing of growth faltering: revisiting implications for interventions. Pediatrics 125, e473-e480.

31. World Health Organization/Pan American Health Organization (2003) Guiding Principles for Complementary Feeding of the Breastfed Child. Washington, DC. WHO/PAHO. http://www.who.int/nutrition/publications/guiding_principles_ compfeeding_breastfed.pdf (accessed June 2013).

32. Shirima R, Greiner T, Kylberg E, et al. (2001) Exclusive breastfeeding is rarely practised in rural and urban Morogoro, Tanzania. Public Health Nutr 4, 147-154.

33. Poggensee G, Schulze K, Moneta I, et al. (2004) Infant feeding practices in western Tanzania and Uganda: implications for infant feeding recommendations for HIV-infected mothers. Trop Med Int Health 9, 477-485.

34. Mosha TCE, Laswai HS \& Tetens I (2000) Nutritional composition and micronutrient status of home made and commercial weaning foods consumed in Tanzania. Plant Foods Hum Nutr 55, 185-205.

35. Arimond M \& Ruel MT (2004) Dietary diversity is associated with child nutritional status: evidence from 11 demographic and health surveys. J Nutr 134, 2579-2585.

36. Rah JH, Akhter N, Semba RD, et al. (2010) Low dietary diversity is a predictor of child stunting in rural Bangladesh. Eur J Clin Nutr 64, 1393-1398.

37. Ntab B, Simondon KB, Milet J, et al. (2005) A young child feeding index is not associated with either height-for-age or height velocity in rural Senegalese children. J Nutr 135, 457-464.

38. Holmboe-Ottesen G \& Wandel M (1991) Wife, today I only had money for pombe. Gender and food; women's bargaining power and agricultural change in a Tanzanian community. In Gender and Change in Developing Countries, pp. 93-119 [Stølen KA and Vaa M, editors]. Oslo: Universitetsforlaget/ Oxford University Press.

39. Food and Agriculture Organization of the United Nations (2011) The State of Food and Agriculture 2010/2011-Women in Agriculture: Closing the Gender Gap. Rome: FAO. http://www.fao.org/docrep/013/i2050e/i2050e.pdf (accessed June 2013).

40. Abubakar A, Holding P, Mwangome M, et al. (2011) Maternal perceptions of factors contributing to severe under-nutrition among children in a rural African setting. Rural Remote Health 11, 1423 .

41. Kulwa KBM, Kinabo JLD \& Modest B (2006) Constraints on good child-care practices and nutritional status in urban Dar es Salaam, Tanzania. Food Nutr Bull 27, 237-244.

42. Pierre-Louis JN, Sanjur D, Nesheim MC, et al. (2007) Maternal income-generating activities, child care, and child nutrition in Mali. Food Nutr Bull 28, 67-75.

43. Engle PL, Menon P \& Haddad L (1999) Care and nutrition: concepts and measurements. World Dev 27, 1309-1337.

44. Joint United Nations Program on HIV/AIDS (UNAIDS) HIV/AIDS Epidemiological Factsheet Tanzania (2008). http://www.unaids.org/en/regionscountries/countries/unitedre publicoftanzania/ (accessed July 2013).

45. World Health Organization (2013) Impact of HIV/AIDS on older people in Africa. http://www.who.int/ageing/projects/ hiv/en/ (accessed July 2013) 